\title{
Textos
}

CLORINDA MATTO DE TURNER

\section{Las obreras del pensamiento en la América del Sur (1895) ${ }^{1}$ (Lectura hecha por la autora en el Ateneo de Buenos Aires, el 14 de diciembre de 1895)}

\section{I \\ CABALLEROS, SEÑORAS:}

La bondad, que da alientos tan gratos como aroma los juncos de la pampa, y no el merecimiento científico o literario, me franquea los escalones de esta tribuna, desde donde se han desarrollado temas ilustrativos para la humanidad y de vital interés para el adelanto intelectual argentino.

Invitada por el muy digno presidente del Ateneo, señor Carlos Vega Belgrano ${ }^{2}$, para dar una conferencia pública, no podía responder a tan honrosa distinción de otra manera que, aceptándola con la expresión de una voluntad diligente.

Nada nuevo traigo.

Mujer, e interesada en todo lo que atañe a mi sexo, he de consagrarle el contingente de mis esfuerzos que, seguramente, en el rol de la ilustración que la mujer ha alcanzado en los postrimeros días del siglo llamado admirable, será un grano de incienso depositado en el fuego sacro que impulsa el carro del progreso, y, aunque éste no producirá la columna de luz que se levanta en los Estados Unidos del Norte, pretendiendo abarcar la América, él dará, siquiera, la blanquecina espiral que perfuma el santuario.

\section{II}

A semejanza de los Sannyassis-Nirwanys de los Vedas, que enseñaban en voz baja, en las criptas de los templos, plegarias y evocaciones que jamás se escribieron, la mujer, silenciosa y resignada, cruzó barreras de siglos repitiendo apenas, con miedoso sigilo, las mágicas palabras: libertad, derecho.

Así como del choque de la piedra pedernal y el acero brota la chispa, al golpe de dos martillazos, uno en el Gólgota, otro en la Bastilla, centelló la luz para la causa de la mujer, quedando en la ceniza del oscurantismo las cadenas que sujetaban su cuerpo y embrutecían su alma.

1 Este texto está extraído del libro Aves sin nido publicado en la editorial Sendes de la Universitat Jaume I de Castellón.

2 Carlos Vega Belgrano, presidente del Ateneo de Buenos Aires, fue más tarde el segundo director de la Biblioteca Pública de la Universidad Nacional de la Plata, 1908-1930. 
El cristianismo, con su antorcha novadora, despidió las tinieblas, y en las róseas claridades de la nueva era, apareció Jesús, quien, no permitiendo que se prosternara a sus pies la pecadora de Naim, practica la doctrina que enseña. El filósofo Dios de la dulce mirada y de túnica inconsútil, patrocina los derechos de la mujer, destinada a ser la compañera del varón, y, como la llama Jacolliot, descanso del trabajo; consuelo de la desgracia ${ }^{3}$.

Su causa, empero, ¿quedaba triunfante al pie del árbol simbólico donde cayeron, como perlas de Oriente, las lágrimas de la enamorada de Magdala? ${ }^{4}$

¡No!

Los obscurantismos, los protervos y los egoístas interesados en conservar a la mujer como instrumento del placer y de obediencia pasiva, acumulan el contingente opositor; la cámara obscura para lo que ya brilla con luz propia, sin fijarse en que, de la desigualdad absoluta entre el hombre y la mujer, nace el divorcio del alma y del cuerpo en lo que llaman matrimonio, esa unión monstruo cuando no existe el amor.

La lucha se inició.

Por una parte batalla el Egoísmo, vestido con las ya raídas telas de la reyecía y el feudalismo; por otra, la Razón, engalanada con atavíos de la Libertad y alentada por la Justicia.

Lucha heroica entre lo viejo y lo nuevo: de la noche con la alborada, bajo el cielo republicano.

El último martillazo dado por los hombres de blusa rayada en los alcázares monárquicos decidió el asunto, echando por tierra el carcomido edificio, y, de entre las ruinas del pasado oprobioso, aparece la figura de la mujer con arreos de la victoria, alta la frente, alumbrada por los resplandores de la inteligencia consciente; fuerte el brazo por el deber, y la personería.

Surgen también espíritus retemplados con el vigor de los cuerpos sanos, que, estudiando la naturaleza y condiciones sociales de la época, comprendieron que postergar la ilustración de la mujer es retardar la ilustración de la humanidad; y nobles, se lanzan como paladines de la cruzada redentora.

En nuestro planeta, todo tiene que regirse por las leyes de la Naturaleza; por ellas el débil busca la protección del fuerte. La gota de agua vive de la nube; la nube de la mar. «La endeble enredadera busca la tapia para trepar el tronco del árbol para circundarlo». La mujer necesitaba el concurso del cerebro masculino para que, sirviéndole de guía, la condujera a la meta anhelada.

Ya tenía apoyo en el corazón del hombre ilustrado. La nube negra que escondía el astro de la personalidad de la mujer, vino a disiparse con la proclamación del principio sociológico: el trabajo con libertad, dignifica; el trabajo con esclavitud, humilla.

3 Biblie dans l'Inde [CMT]. El interés por el cristianismo originario fue una constante en la ideología de Clorinda Matto. Este cristianismo tiene menos que ver con la Iglesia como organización estructurada y más con el mensaje libertador de Jesucristo. No olvidemos que la autora tradujo al quechua varios libros del Evangelio.

4 Esta referencia a la «Magdala» puede referirse al cuento «La Magdala», de Coelho Netto, que se publicó en la revista El Perú Ilustrado cuando Matto era su directora. Este cuento causó gran revuelo entre la jerarquía católica, que inició una ofensiva contra la autora y la revista. 
Las palabras del erudito tuvieron eco de repercusión simpática en la patria donde se rinde culto a esa libertad invocada en el altar de la igualdad.

Si queréis reinar sobre cuerpos de esclavos y sobre conciencias embrutecidas -dice el autor que cité antes- hay un medio de sencillez sin igual que nos muestra la historia de las épocas vergonzosas: degradad a la mujer, pervertid su sentido moral y pronto habréis hecho del hombre un ser envilecido, sin fuerzas para luchar contra los más sombríos despotismos, iporque la mujer es el alma de la humanidad!

Pero bien.

La redención de toda esclavitud, el triunfo de toda idea grandiosa, han necesitado de sangre, como si el licor de la vida del hombre fuese el abono que los fructificara; sólo la causa de la ilustración de la mujer no ha necesitado más que paciencia, con el heroísmo del silencio, después, audacia sobre el pedestal de la perseverancia.

En estas condiciones se sembró la semilla que, germinando durante tan enorme lapso de tiempo, brotó y se desarrolla, con proporciones gigantescas en el terreno fértil de nuestra América.

Hoy, puede afirmarse que es ya el árbol fuerte como los cedros bíblicos, bajo cuya fronda trabajaban millares de mujeres productoras que, no sólo dan hijos a la patria, sino, iprosperidad y gloria!

Estas son LAS OBRERAS DEL PENSAMIENTO, de quienes voy a ocuparme en seguida ${ }^{5}$.

\section{III}

No buscaremos en la patria de Washington el lago plácido para beber las noticias sobre el progreso intelectual de la mujer americana; que allá todo es grandioso, y, más de cuatro mil empleadas en el servicio civil del gobierno, más de tres mil periodistas, escritoras y traductoras; cerca de cuatro mil empleadas en las notarías, en los bancos y casas comerciales, y todo el cuerpo docente educacionista del estado, fuera de las que ejercen la cirugía y la medicina, nos dirían, parafraseando a Miss Alice Mc. Guilleway ${ }^{6}$ el puente levadizo que cerraba la entrada de la mujer al palacio encantado del saber, del trabajo y de la fortuna, ha caído derribado para siempre por las exigencias de la época y la protección de los hombres.

El ilustre Bolet Peraza ${ }^{7}$ agregaría: escuelas, talleres, universidades, academias, cortes, tribunales: por todas partes la mujer en actividad fecunda. No hay que alarmarse por ese estallido de la antigua costra social que se resquebraja.

5 A partir de este punto Matto da cuenta, a vista de pájaro, de muchas de las mujeres que contribuyeron con su aportación a diversos campos sociales en América Latina. Mary Louise Pratt (1995) destaca la inserción en los ensayos de las escritoras decimonónicas de «catálogos históricos», consistentes en la enumeración de mujeres que destacaron en la historia, como una de las categorías discursivas del «gender essay» (ensayo de género). Véase Pratt, Mary Louise (1995): «Don't Interrupt me. The Gender Essay as Conversation and Countercanon». En: Meyer, Doris (ed.) Reinterpreting the Spanish American Essay. Women Writers of the 19th and 20th Centuries. Austin: University of Texas Press, pp. 10-26.

6 No encontramos ninguna referencia a esta autora mencionada por Matto.

7 Nicanor Bolet Peraza (1838-1906), escritor costumbrista, periodista y orador venezolano. Dirigió la prestigiosa Revista Ilustrada de Nueva York y fue fundador de Las Tres Américas. 
Es que la mujer toma posesión de sus derechos.

Es la sociedad que se perfecciona.

Es la humanidad que se completa.

Concentremos nuestra mirada hacia las repúblicas del sur y centro de América: son las que más cerca interesan a nuestra raza y a nuestro idioma.

Para ocuparnos, de una vez, del estado de la ilustración de la mujer americana, la buscaremos en aquellas que, porta-estandartes de la legión empeñada en la gran evolución social, han desafiado, desde la ira alta, hasta el ridículo bajo, para ir siempre adelante con la enseña civilizadora.

Me refiero a las mujeres que escriben, verdaderas heroínas que, con el valor de Policarpa Salavarrieta ${ }^{8}$, aceptando la muerte antes que delatar los secretos de su patria y con la convicción de los mártires en la verdad de la obra, luchan, día a día, hora tras hora, para producir el libro, el folleto, el periódico, encarnados en el ideal del progreso femenino.

Y ¿con qué aliciente?

La gloria. ¡Oh, la gloria, que casi siempre arroja sus laureles sobre ataúd, donde han caído derribadas por el hambre del cuerpo o los supremos dolores del alma!

¡No importa!

Con la planta herida por los abrojos del camino y la frente iluminada por los resplandores de la fe en los destinos humanos, ellas, las obreras del pensamiento, continuarán laborando.

\section{IV}

La República Argentina, que tiene héroes de la guerra magna, porque sus madres supieron amamantarlos con el seno de las espartanas, habrá de enorgullecerse también de ser la patria de Juana Manuela Gorriti, muerta hace tres años, después de haber ilustrado su época con multitud de libros cuyo número me excusa de la enumeración. Juana Manuela, rodeada del respeto y de la admiración, no por haber sido esposa y madre de presidentes de una república ${ }^{9}$, sino por haber sido escritora.

Eduarda Mansilla de García, la fantástica Eduarda, hermana de un general, madre de un marino distinguido, no vivirá en la posteridad por ellos, sino por sus obras.

Las de mayor notoriedad son, el libro de viajes y la novela titulada El médico de San Luis.

Josefina Pelliza de Sagasta, la noble dama de elevados pensamientos que escribió por la mujer y para la mujer; arrebatada a la vida en horas preciosas, dejó un

8 Policarpa Salavarrieta (1795-1817), conocida como La Pola, es la heroína colombiana más popular de la épcoa independentista a principios del siglo XIX, que no se amilanó ante la violencia de los españoles, contra los que luchó por la independencia, hecho por el cual fue ejecutada. La muerte de la Pola es reivindicada por la población contra la barbarie impuesta por Juan Sámano, último virrey español en la época de la reconquista.

9 Se refiere al hecho de que Gorriti se casó con un soldado, Isidoro Belzú, quien más tarde llegó a ser presidente de Bolivia (1848-1855). 
volumen de Conferencias educacionistas filosóficas; y la señora Juana Manso, cuya labor sobre educación fue tan fecunda en resultados, son las mujeres argentinas que ya entregaron a Dios su espíritu abrillantado por la ilustración y purificado en el crisol del heroísmo porque ellas, más que las de la presente generación, tuvieron que sostener lucha tenaz contra las preocupaciones, pues lo que en Europa y América del Norte constituye una profesión honrosa y lucrativa, en América del Sur es casi un defecto.

Los nombres que he mencionado bastarían para la gloria literaria de un pueblo; no obstante, aún tengo otros que agregar: Ana Pintos, que tan galanamente maneja el idioma, escondida tras el seudónimo de Amelia Palma; Amalia Solano, de las nutridas revistas; Carlota Garrido de la Peña, autora de las novelas Mundana y Tila; María Emilia Passicót, Eufrasia Cabral, Aquilina Vidal de Bruss, María E. Cordero, Adela A. Quiroga, Isabel Coronado, María Luisa Garay, Elena Jurado, María Brown, Arnold de González, Benita Campos, Elia M. Martínez, Yole Zolezzi, Macedonia Amavet, C. Espinosa, la señora de Funes y algunas otras que tal vez no he alcanzado a conocer, son, pues, las que hoy forman la legión de honor en la patria de Alberdi y de Sarmiento, con la particularidad de que las más de ellas son de provincias, muy pocas de esta gran Buenos Aires, con propiedad llamada la Nueva York del Sur.

En la patria uruguaya, donde se guarda la bandera de los Treinta y Tres ${ }^{10}$ y se hace memoria de los héroes que «tomaron a ponchazos» los cañones del enemigo, pulsan la lira de Apolo dos hermanas en la sangre y en el arte: Dorila Castell de Orozco y Adela Castell. Tierna como paloma la primera, canta para las almas sedientas de consuelo, y si abandona esa entonación, es cuando el patriotismo la exalta. Las composiciones tituladas Un día más, Anhelos, Dudas, La campesina, son las más popularizadas; pero las mejores formarán un volumen próximo a publicarse, cuyos originales deleitaron las horas que pasé en la culta Montevideo.

Más asimilada al modernismo, Adela, burila sobre planchas de concha madre, estrofas filosóficas, como las siguientes que tomo del perfumado manojo, siempre al alcance del gusto:

¿Cómo tu imagen fue a quedar grabada

Cual con buril de acero

En mi intranquila y soñadora mente?

No ves que no lo entiendo...

¿Cómo en nerviosa célula es que pudo

Fijarse tu recuerdo?

Si tu recuerdo es sol ¿cómo engarzado

Quedó en marco de nervio?

No comprendo por más que me lo expliques

Ni llegaré a entenderlo,

10 Se refiere a la Bandera de los Treinta y Tres Orientales, creada en Uruguay por la Ley del 26 de agosto de 1825 para rememorar el Desembarco de treinta y tres soldados en la Playa de la Agraciada, el 19 de abril de 1825, para iniciar la lucha contra España por la libertad de Uruguay. 
Corriente cerebral que sea el cariño...

¡Materia el pensamiento!...

¡Ah, qué extraño problema! Me parece

que no he de resolverlo;

Renuncia a creer que tengo un alma

Si con otra yo sueño...

Junto a las dos poetisas ya de renombre americano, están como capullos que se abren llenos de perfume y colores, Ernestina Méndez Reissig y María Vaz Ferreyra, presuntas glorias uruguayas; y como pensadora elegante y concisa, Casiana Flores ${ }^{11}$.

No olvidaré a Lola Larrosa de Ansaldo, autora de las novelas El lujo, Los esposos, Hija mía, así como de trabajos sueltos, unos reunidos en un tomo con el nombre de Ecos del corazón, esparcidos otros en diarios y revistas. Lola, que apenas a los 38 años de existencia, el 25 de Septiembre último, vistió el sudario de la muerte, en condiciones dolorosas que no es del caso recordar.

Carezco de noticias sobre la república del Paraguay y cambiaremos de rumbo.

No detendrá nuestra atención Sor Úrsula Suárez. La ilustre Mercedes Marín del Solar, autora de la magistral oda A la muerte de Diego Portales, y de cincelados sonetos. Luisa Montt de Montt, delicada, afectuosa, con flores primaverales en búcaro de alabastro; Delfina María Hidalgo de Marín, Carlota Joaquina Bustamante y Rosario Orrego de Uribe, son las que, entre otras, han sobresalido en Chile, así en la prosa seria como en el verso fluido.

Bolivia, la patria de las mujeres de Cochabamba, tiene a Mercedes Belzú de Dorado $^{12}$, la ferviente traductora de los Salmos de David, autora de composiciones magníficas como el canto Al Misti, hecho después de contemplar el volcán a cuyas faldas se encuentra la ciudad de Arequipa, del territorio peruano.

María Josefa Mujía, la pobre ciega que conmueve el alma cuando nos dice:

¡Todo es noche, noche oscura!

Ya no veo la hermosura

De la luna refulgente;

Del astro resplandeciente

¡Tan sólo siento el calor!

Las inteligentes Adela Zamudio, Natalia Palacios y la señora de Campero ${ }^{13}$, completan las noticias que de aquella república tengo.

11 «Ya falleció esta escritora» [CMT]

12 Mercedes Belzú fue la hija de la escritora Juana Manuela Gorriti (1819-1892) con el que llegaría a ser presidente de Bolivia, Isidoro Belzú.

13 «La señora Lindaura A. de Campero falleció en el año de 1898» [CMT]. 
La desventurada Dolores Veintemilla de Galindo ${ }^{14}$; Dolores Sucre, la democrática cantora del Carpintero; Marieta Veintemilla, autora de Páginas del Ecuador, libro que levantó ardiente polémica histórica; Rita Lecumberri, Ángela Caamaño de Vivero, Carmen Pérez de Rodríguez y la señora de González, representan a la patria de Olmedo, y en Colombia encontramos espíritus preparados como el de Soledad Acosta de Samper, laboriosa posadora que acaba de completar sus obras con el libro La mujer, publicado en París. Agripina Samper de Ancisar, muerta en la plenitud de la fuerza creadora, enriqueció el parnaso colombiano bajo el anagrama de «Pía Rigan», Elena Miralla Zuleta, espíritu batallador, reverso de la medalla, con Silveria Espinosa de Rendón, la mística poetisa que cantó a la Cruz y murió en esa cruz esperando. Agripina Montes del Valle y la aplaudida Mercedes Álvarez de Flores, la de los versos de fuego en tarde de tempestad. Sus estrofas en Sueño a Él y otras, son hechas con saeta eléctrica para exaltar los corazones fríos. A este nombre agregaremos los de Josefa Acevedo, Isabel B. de Cortés, Waldina Dávila de Ponce y la señora Párraga de Quijarro.

México es la nación que ha dado mayor número de escritoras. A noventa y cinco llega la cifra de poetisas en la colección publicada en el año 93 por Vigil, bajo la protección de Carmen Rubio de Díaz, la esclarecida y simpática protectora de las ideas nobles en la tierra del Anahuac.

Enumerarlas sería extender mucho este bosquejo, así es que, sin remontarnos hasta sor Juana Inés de la Cruz ${ }^{15}$, poetisa de los sublimes histerismos de Teresa de Jesús, recordaremos a Esther Tapia de Castellanos, Dolores Guerrero, Severa Aróstegui y Laura Méndez de Cuenca. Esta última es una poetisa de un vigor sorprendente. Sus estrofas parecen hechas con el escalpelo anatómico que tritura la carne mórbida de igual manera que los nervios crispados o en tensión. Si Laura Méndez de Cuenca no tuviese tantas composiciones y rico bagaje literario en el periodismo, la que titula ;Oh corazón! le bastaría para renombre como poetisa de primer orden.

La república de San Salvador, tan fecunda en hombres de letras, acaba de perder a la genial poetisa Antonia Galindo, que era de pocas mujeres que allá han publicado algo.

Otro tanto diré de Venezuela, citando a Carmen Brige, donde la espiritual Polita de Lima al frente de la «Sociedad Alegría», de Coro trabaja por el brillo de las letras venezolanas y persigue con tesón la verdadera y recíproca ilustración del hombre y de la mujer.

Y en verdad que si la mujer se ocupase más de estudiar las aficiones y el carácter del esposo para colmarlo de las complacencias del hogar, desaparecería esa riva-

14 Dolores Veintemilla (1830-1857) se suicidó después de lanzar una campaña en contra de la pena de muerte, campaña que hizo de ella una paria social. Fue amiga intelectual de Ricardo Palma y Guillermo Blest Gana. Su ensayo en contra de la pena de muerte sobrevive en la semblanza que Ricardo Palma le dedicó: «Dolores Veintemilla. Apuntes de mi cartera». Tradiciones peruanas completas. Ed. Edith Palma. Madrid: Aguilar, 1964, pp. 1422-1430.

15 Quizá la escritora más estudiada de Latinoamérica, la mexicana Sor Juna Inés de la Cruz (1651-1695) participó en la vida intelectual del virreinato de la Nueva España. Véase un reciente y espléndido análisis de la obra de Sor Juana en: Glantz, Margo (2005) La desnudez como naufragio. Borrones y borradores. Madrid/Frankfurt: Iberoamaericana/Vervuert. 
lidad que existe entre la casa y el club, nacida sólo de la preocupación de muchas que, erradamente, creen que el pretendiente cuando deja de ser tal, entra en el rol de siervo.

El simpático y querido nombre de Rafaela de Darío responde galanamente a la historia literaria contemporánea de Guatemala; en Nicaragua parece que impulsan las letras las hermanas Selva; y en Nueva Granada, Dolores Haro.

En las repúblicas de Costa Rica, Dominicana y de Honduras, sólo podría citar seudónimos como «Esther», «María» y otros que, unas veces son el velo de la natural timidez y otros originan chascos literarios, como el de Edda, con el que escribió Rafael Pombo; Leonor Manrique seudónimo de Vicente Holguín, escritor colombiano, y el de Rebeca, de Fernando Guachalla, boliviano.

Tócame, en fin, ocuparme del Perú, mi amada patria, cuyo pabellón blanco y rojo, hecho con la sangre de los héroes de la independencia y el velo de las vírgenes del sol $^{16}$, fue glorificado por mujeres de la talla de Francisca Zubiaga, esposa del generalísimo Agustín Gamarra.

Carolina Freyre de Jaimes ${ }^{17}$, poetisa y prosadora elegante, hija de la ciudad de Tacna una de las cautivas de la guerra del Pacífico, ha hecho el paseo triunfal hollando palmas desde el teatro con sus dramas Pizarro, Maria de Vellido, Blanco de Silva, hasta las columnas del semanario pulcro y el diario vertiginoso.

El periodismo femenino debe a Carolina Freyre de Jaimes páginas como de $E l$ Álbum, que fondo en el Perú y continuó en Bolivia, y, en el bagaje literario de la galana escritora, encontramos, no sólo las novelas cortas tituladas El regalo de boda y Memorias de una reclusa, sino también el poema Sin esperanza y la colección de versos A la memoria de mi hijo Federico, donde brillan las filigranas del alma y las mariposas de oro que revolotean junto a la cuna del hijo, ese supremo bien, pedazo de nuestro propio ser, para quien guardamos todo cuanto de dulce, de noble y de tierno atesora el amor maternal.

Dice la poetisa madre:

\section{A FEDERICO}

Como pálido lirio tronchado

Dobló la cabeza.

Y el fulgor se apagó que animaba

Tan dulce existencia.

16 En el marco de la sociedad inca, la institución religiosa femenina más importante era la de las Vírgenes del Sol, como las llamaron los colonizadores españoles. Se trataba de un grupo de mujeres seleccionadas desde la pubertad, entre las hijas del pueblo y las de la nobleza. Eran educadas y preparadas para cumplir importantes misiones: desde el perfeccionamiento del idioma y las artes domésticas, hasta la iniciación en los secretos de la religión y el culto.

17 Carolina Freyre de Jaimes fue la madre del poeta boliviano Ricardo Jaimes Freyre (1868-1933), nacido en Tacna, propulsor del modernismo boliviano, parte del movimiento en Buenos Aires, que heredó el interés literario de su madre. 
De pulido marfil parecía

$\mathrm{Su}$ forma hechicera,

Sus pupilas dos astros opacos

Tras nube ya densa,

Y sus labios sin vida, la rosa

¡Que el estío quema!...

Rota estatua de mármol vencida

Por ruda tormenta,

Sólo quedan de ti los despojos

Tras muros de piedra.

Mercedes Cabello de Carbonera ${ }^{18}$, natural de la ciudad de Moquegua, la renombrada novelista y pensadora, dejó la lira que pulsaba con la entonación de Aurora para dedicarse a la novela.

Tiene publicadas en este género: Sacrificio y recompensa, Blanca Sol, Los amores de Hortensia, y El conspirador.

Un estudio crítico del ruso León Tolstoï, y los folletos La religión de la humanidad, y La novela moderna, le han conquistado, también, más laureles sobre los que ostenta su frente de reina.

Teresa González, viuda del marino Fanning ${ }^{19}$, muerto gloriosamente en la guerra con Chile, después que vio disiparse la felicidad del hogar junto con la existencia de su esposo, se dedicó al magisterio y a la literatura. Ha hecho algunos versos, muchos magníficos cuadros de costumbres, varios textos de Geografía, Geografía e Historia, un tomo titulado Lucecitas cuyo modesto rubro dice mal con el mérito de la obra.

Juana Rosa de Amézaga ya tenía conquistado el renombre como poetisa de astro vibrante cuando entregó a la prensa su libro Pensamientos y Máximas, donde resalta una labor filosófica y proficua en beneficio de la mujer peruana: sus ideales educacionistas están cristalizados con mano maestra.

Carolina García de Bambaren, poetisa de las dulcedumbres del hogar, acariñada de la lira modulada en el tono melancólico; y a esta escuela pertenecen también Justa García Robledo, talentosa e inspirada, e Isabel de la Fuente.

Juana Manuela Lazo de Eléspuru y su hija Mercedes, cultivan la gaya ciencia con la inspiración; y entre las que han dado el vigor de su cerebro al periodismo, descuella Lastenia Larriva de Llona, directora de El tesoro del hogar, autora de las novelitas Oro y escoria, Oro y oropel y Luz.

18 Mercedes Cabello de Carbonera (1845-1909) además de sus novelas sociales, que Matto menciona en su resumen, también redactó ensayos de mucho valor como Influencia de la mujer en la sociedad (1874), y otros dos que Matto no olvida, La novela moderna (1892) y La Religión de la Humanidad (1893). El primero es muy importante en cuanto a la propuesta moral, así como las posturas de Manuel González Prada, y en cuanto a la idea de que la mujer es la que va a civilizar al hombre, proposición que también aparece en González Prada y en Clorinda Matto. Cabe mencionar una reciente biografía de Cabello que tiene en cuenta su ensayística: Pinto Vargas, Ismael (2003) Sin perdón y sin Olvido. Mercedes Cabello de Carbonera y su mundo. Lima: Universidad de San Martín de Porres.

19 Teresa González de Fanning (1835-1918) fue una destacada escritora y educadora. 
Amalia Puga de Losada, la juvenil musa del parnaso peruano, conquistó los laureles de la popularidad como poetisa, y en la prosa ha descollado cono donosura y buen juicio.

Margarita Práxedes $\mathrm{Muñoz}^{20}$, tiene publicados trabajos científicos sueltos y un libro con el título de La evolución de Paulina. Grimanesa Masías, pensadora delicada, que de vez en cuando entrega al público una florecita velada por el seudónimo; y Rosalía Zapata, cuyo porvenir promete; Adriana Buendía, la donosa niña de la lira de oro, ha derramado profusamente las flores de su ingenio en el camino de la gloria. Para muestra, recordaré la que titula Flores y perlas, dirigida a una amiga de la infancia:

En el cáliz de plata de una azucena,

cierto día la aurora vertió una perla; y el sol ardiente

consumió esa preciosa gota de nieve.

De tus ojos azules brotó una lágrima, y del mar en el fondo quedó guardada. ¡Qué feliz reina será la que consiga tan linda perla!

Fabiana de Dianderas, alma poética, consagrada sólo a la musa del hogar, ha cantado a su madre, a su hermano, a sus hijas, y ha llorado en la muerte de Daniel Matto con la espontaneidad del ruiseñor que gorjea notas ora dulces, ora tristes.

La gentil Matilde Guerra de Miró Quesada, cuya pluma ostenta la fluidez del estilo en prosa correcta y atrayente.

Ángela Carbonell, la picaresca y festiva escritora que tanto lustre dio a La Alborada y a La perla del Rímac, ha obsequiado a la prensa sus magistrales traducciones francesas con todo el galano decir de Víctor Hugo o el incisivo lenguaje de Balzac.

Estas son las que actualmente sostienen el torneo intelectual dentro y fuera de la república; tal vez he olvidado a algunas con el deseo de recordar, cuanto antes, a las que temprano murieron, dejando en las filas claros de luz.

Manuela Villarán de Plasencia fue una poetisa festiva e ingeniosa. Sobre su frente parpadeaba siempre el astro de la mañana.

20 Margarita Práxedes Muñoz fue la primera mujer que obtuvo en la Universidad Mayor de San Marcos (Lima, Perú) el grado universitario de Psiquiatría. Ejerció en Santiago de Chile y en Argentina. De hecho, Margarita Práxedes y Trinidad María Enríquez (1846-1891), profesora de Matto en la etapa escolar de ésta en Cuzco, fueron las primeras mujeres peruanas en obtener un título universitario. 
La composición En un campanario, es un modelo del género que cultivó; pero cuando el plomo de la guerra del 79 le quitó a su hijo Ernesto, esa alma desbordante de amargura lloró sobre la lira enlutada y de sus quejidos brotaron las magistrales estrofas A Ernesto. Madre esposa modelo, amiga incomparable; su muerte fue un dolor patrio.

Leonor Saury, la dulce Leonor, de la lira de marfil, pulsada siempre con los ojos levantados hacia el cielo. Todos sus versos son filigranas de plata con fondo azul; su vida, comparable con la de una gardenia, fue todo un perfume y duró tan sólo una mañana.

Manuela Antonia Márquez, poetisa de sangre escribió poco, pero bueno, y la música acompañó a su musa. Compuso una zarzuela, cuyo libreto, con el título de La novia del colegial, hizo su hermano Luis Márquez. Murió en la plenitud de la vida; su nombre es una gloria de familia.

Carmen Póts de Pérez Uribe y María Natividad Cortés, también pertenecían al número de las escritoras con los nobles anhelos femeninos; así como Trinidad María Enríquez, cuzqueña audaz, fue la primera que en el Perú acometió las aulas universitarias en la facultad de jurisprudencia.

Escribió en prosa correcta, fundó un colegio para señoritas y una escuela para artesanos donde ella misma daba lecciones a los obreros.

La estrechez del escenario tal vez asfixió esa alma generosa: el vendaval del infortunio la arrastró, despiadado, hacia temprana sepultura; pero su nombre está escrito en el corazón del pueblo y no la olvida el país nativo.

\section{V}

Bastante he fatigado ya vuestra atención y os pido excusa.

La enumeración, aunque incompleta, que he hecho, sirva de recuerdo agradecido para las obreras del pensamiento en América del Sur; verdaderas heroínas, repito, que no sólo tienen que luchar contra la calumnia, la rivalidad, el indiferentismo y toda clase de dificultades para obtener elementos de instrucción, sino hasta correr el peligro de quedarse para tías, porque, si algunos hombres de talento procuran acercarse a la mujer ilustrada, los tontos le tienen miedo.

¡Ah, no es tan desgraciado el ciego de nacimiento, sin idea de luz y color, como aquel que, en hora triste, sintió hundirse en la noche eterna la vida de las pupilas!

Consideremos por este símil la situación de la mujer que está en lucha abierta entre la ceguera que amenaza y la luz que es preciso dilatar. 